\title{
Sulfur-Containing Activated Carbons With Greatly Reduced Content of Bottle Neck Pores For Double-Layer Capacitors: A Case Study For Pseudocapacitance Detection
}

\author{
${ }_{5}$ Wentian Gu, ${ }^{a}$ Marta Sevilla, ${ }^{b}$ Alexandre Magasinski, ${ }^{a}$ Antonio B. Fuertes, ${ }^{b}$ and Gleb Yushin ${ }^{* a}$ \\ Received (in $X X X, X X X) X$ th $X X X X X X X X X 20 X X$, Accepted $X$ th $X X X X X X X X X 20 X X$ \\ DOI: 10.1039/b000000x
}

Synthesis of S-doped activated carbons (ACs) by carbonization and simultaneous activation of S-based polymers was found to be an efficient route to produce porous carbons for double layer capacitors (EDLCs) with high specific energy and power densities combined 10 with low self-discharge. Here we investigate for the first time the processing-structure-property relationships related to the formation of polythiophene-derived ACs for EDLC applications. Sulfide bridges present in the polymer precursor were found to depress the shrinkage of the smallest micropores during the carbonization process and allow for the enhanced ion transport within the produced AC electrodes. The cyclic voltammetry (CV) measurements on S-doped ACs produced at 800 and $850{ }^{\circ} \mathrm{C}$ showed high specific capacitance (up to $\sim 200$ $\mathrm{Fg}^{-1}$ ) and no significant self-discharge in neutral aqueous electrolytes. More importantly, these capacitance values remained virtually 15 identical for a sweep rate increasing from 1 to $50 \mathrm{mVs}^{-1}$. The observed capacitance retention is quite remarkable for thick electrodes of $\sim 200 \mu \mathrm{m}$ and large AC particle size of 10-100 $\mu \mathrm{m}$. It indicates great potential of the proposed synthesis technology for EDLC operating at high frequencies and high currents. In the course of our systematic studies of AC performance in different electrolytes we found a strong correlation between the large pseudocapacitance and the significant self-discharge in ACs. We harness the difference between the characteristic times required to establish a double layer and that of the pseudocapacitive redox reactions and propose a simple method to

20 estimate the fraction of pseudocapacitance. The proposed method is particularly valuable in cases when CV measurements do not show clear characteristic reduction-oxidation peaks.

Keywords: supercapacitor, microporous, mesoporous, carbon, graphene, nanotube, doping, leakage, self-discharge, pseudocapacitance, functional groups

\section{${ }_{25}$ 1. Introduction}

In the field of electrical energy storage, electrochemical capacitors (ECs) technology offering a combination of high specific power, and stable operation under short term high current pulses even in the case of full discharge ${ }^{1,2}$ is an indispensible 30 complement to Li-ion batteries. Potential applications of ECs range from power supplies for memories in micro-computers to rapid heating devices in copiers and industrial printers to power for on-demand lighting on roads to electrical motors in hybrid electric vehicles and industrial equipment to power sources in 35 lasers, to name a few. The majority of commercial ECs are believed to function as electrical double layer capacitors (EDLCs), where the energy storage is purely electrostatic and virtually no charge transfer takes place across the electrodeelectrolyte interface. Micro- and meso-porous carbons utilized in

40 EC/EDLC electrodes have shown steady developments during the last decade and demonstrated increased specific and volumetric capacitance ${ }^{3-5}$ and longer EC cycle life. ${ }^{6-8}$ The contribution of reduction/oxidation (redox) pseudocapacitance reactions to

${ }^{a}$ School of Materials Science and Engineering, Georgia Institute of 45 Technology, Atlanta, GA, USA

${ }^{b}$ Instituto Nacional del Carbón (CSIC), P.O. Box 73, 33080 Oviedo, Spain

"Corresponding author email: yushin@gatech.edu the double layer capacitance of porous carbons may potentially likely to dominate commercial EC applications due to their 75 comparable and often superior performance combined with wellestablished manufacturing. ${ }^{41-43}$ The recent advancements in AC synthesis from organic natural $41,44-49$ or synthetic $42,44,50,51$ precursors show rapid progress. To further advance the performance of ACs one needs to fine-tune synthesis techniques 80 to optimize carbon pore size distribution and to maximize the
${ }_{50}$ enhance their energy storage ability ${ }^{9,}{ }^{10}$, but could also lead to undesirable leakage currents and device degradation ${ }^{10,11}$ with cycling and/or storage, particularly at elevated temperatures. Unfortunately, the detection of pseudocapacitance contributions, required for systematic studies and material optimization, is not a 55 trivial task since cyclic voltammetry (CV) curves may exhibit no evident peaks. This is because the enthalpies of various ionelectrode interactions on the surface of electrode materials may exhibit a very broad distribution. In fact, even the "classical" pseudocapacitance materials, such as hydrous ruthenium oxide, 60 may show no characteristic peaks and exhibit a rectangular shape of the CV curves. ${ }^{12,13}$

Desirable properties of porous carbons for the majority of EC applications include high volumetric capacity (and therefore high particle density and high particle packing factor), the lack of ${ }_{65}$ uncontrolled side reactions with electrolyte (to achieve low selfdischarge and long cycle life), scalable low-cost synthesis and consistent properties (such as pore size distribution, density, impurity content and surface functionalities). While several interesting methods have recently been explored for the 70 microporous carbon synthesis, such as zeolite- ${ }^{14-21}$ and/or mesoporous silica ${ }^{22-25}$ templating, soft templating ${ }^{26,27}$, and the use of inorganic carbide precursors for carbide-derived carbon synthesis ${ }^{22-24,27-40}$, to mention a few, activated carbons (AC) will

surface area accessible by electrolyte ions. Both too large $31,32,48$, 52,53 and too small ${ }^{48,53-56}$ pores are known to offer inferior capacitance. During AC synthesis very small pores (not accessible by electrolyte ions in ECs) are formed by the shrinkage ${ }_{85}$ of the material during carbonization of organic precursors at high temperatures. ${ }^{57}$

To depress the pore shrinkage of micropores and therefore 
better match the pore size with charge carriers in the electrolyte, Hasegawa et al. ${ }^{58}$ proposed sulfonation of carbon precursor by intensive acid treatment. Sulfur-containing functional groups were proposed to support the larger pores and avoid their collapse 5 or shrinkage at high temperatures. However, acidic treatments offer rather poor control over the uniformity and distribution of S-containing functional groups in ACs. In addition, the pseudocapacitive reactions in EC induced by acid oxidations may, in principle, lead to undesirable self-discharge and device 10 degradation. ${ }^{10}$

In this work, we report for the first time how the intrinsic sulfur (S) - doping of activated carbon may reduce the content of the smallest bottleneck micropores and enhance the rate capability of EDLC electrodes. In the course of our study we 15 systematically investigate how synthesis conditions of S-doped ACs influence their pore size distribution, specific surface area, microstructure and chemistry. We also reveal how the physical and chemical properties of these AC affect their electrochemical performance in different aqueous electrolytes. More importantly, 20 by using some of such carbons, we demonstrate that simple kinetic studies of cyclic voltammograms allow one to distinguish between slow pseudocapacitive reactions and faster double layer adsorption within microporous carbon electrodes.

\section{Experimental}

25 For the synthesis of S-doped carbon, 2-thiophenemethanol (Aldrich) in $\mathrm{CH}_{3} \mathrm{CN}$ was slowly added to $\mathrm{FeCl}_{3}$ solution in $\mathrm{CH}_{3} \mathrm{CN}$. After kept under stirring for $15 \mathrm{~h}$, the mixture was filtered and PTh was separated. The obtained polythiophene (PTh) was then washed with distilled water and then acetone. The ${ }_{30}$ clean PTh was dried at $120^{\circ} \mathrm{C}$ for several hours. The PTh was activated by heating up at 600,800 and $850{ }^{\circ} \mathrm{C}$ with $\mathrm{KOH}$ for 1 hour. The KOH/PTh ratio is 2 for all the samples. To remove any residual inorganic salts, the activated samples were washed with 10 wt. $\% \mathrm{HCl}$ and then distilled water until a neutral $\mathrm{pH}$ was 35 achieved. Finally, the samples were dried at $120^{\circ} \mathrm{C}$ overnight to remove all the remaining solvents and moisture. ${ }^{59}$ The samples were labeled according to the annealing temperature as AC-600, $\mathrm{AC}-800$ and $\mathrm{AC}-850$ for 600,800 and $850^{\circ} \mathrm{C}$ respectively. Mesoporous activated carbon (CECA, 4S) was used for 40 comparison purposes.

The morphology of all the samples was characterized using a scanning electron microscope (SEM) (LEO, Germany). All the samples were additionally studied under a transmission electron microscope (TEM) (JEOL, Japan). A LECO Tru Spec

45 microanalyzer was used to calculate the $(\mathrm{C}, \mathrm{H}, \mathrm{O})$ composition of the materials. The sulfur content of the samples was determined by means of a LECO S-632 analyzer. The surface analysis of the samples was completed by Thermal K-Alpha X-ray photoelectron spectroscopy (XPS). The structural characterization of tested 50 samples was additionally performed by using Raman spectroscopy. Nitrogen sorption-desorption isotherms have been collected at 77K using a ASAP 2020 (Micromeritics, USA) in order to determine the surface area and pore size distribution of the samples. The BET surface area was calculated from the 55 isotherms in the range from 0.02 to 0.2 of relative pressures $\left(\mathrm{P} / \mathrm{P}_{0}\right)$. Non-local density functional theory (NLDFT) calculations utilized for pore size distribution measurements assumed slit shape of the carbon pores.

All electrochemical measurements in this study were 60 performed in symmetric beaker cells. Gold thin foils were used as current collector. Celgard 2325 membrane was used as separator. We used a suspension of the Polytetrafluoroethylene (PTFE) (Aldrich, $60 \mathrm{wt}$ \% in water) as a fibrous binder. The total amount of the binder in electrodes was kept at $15 \mathrm{wt}$. \%. The electrodes ${ }_{65}$ were thoroughly dried overnight and then assembled in beaker cells. The thickness of the electrodes was controlled at around $200 \mu \mathrm{m}$. The following electrolyte solutions have been selected for the study: $6 \mathrm{M}$ lithium chloride $(\mathrm{LiCl}), 1 \mathrm{M}$ hydrochloride $(\mathrm{HCl})$ and $0.5 \mathrm{M}$ sulfuric acid $\left(\mathrm{H}_{2} \mathrm{SO}_{4}\right)$ aqueous solutions. Cyclic 70 voltammetry $(\mathrm{CV})$ measurements were performed using a 1250 Galvanostat/Potentiostat (Solartron Instruments, USA) at different constant scan rate $\left(1-500 \mathrm{mV} \mathrm{s}^{-1}\right)$ between $-0.6 \mathrm{~V}$ and $0.6 \mathrm{~V}$. The capacitance of a symmetric cell was deduced from the loop area by the relation $C=A /(2 \Delta V)$, where $C$ is the cell 75 capacitance, $A$ is the loop area and $\Delta V$ the potential window. With the assumption that two electrodes assembled together are equal in capacitance, the capacitance of each electrode is double the value of the whole cell. Charge-discharge measurements were performed using a SCTS supercapacitor testing system (Arbin 80 Instruments, USA) in the range of constant current densities (50 $10000 \mathrm{~mA} \mathrm{~g}^{-1}$ ) between -0.6 and $0.6 \mathrm{~V}$. The capacitance was deduced from the charge-discharge curves by the relation $C=I /(d V / d t)$, where $C$ is the cell capacitance, $I$ is the current, $d V / d t$ is the average slope of the discharge curve. Electrochemical ${ }_{85}$ impedance spectra (EIS) was performed by Gamry Reference 600 Potentiostat. Nyquist plots and Bode plots are recorded for characterization of impedance of tested samples. The EIS was performed within $10^{-2}-10^{6} \mathrm{~Hz}$ frequency range.

\section{Results and Discussions}

\section{3.1. Structural and chemical properties of the as-prepared S- doped activated carbons}

The SEM studies revealed the average particle size of the produced ACs to range from 10 to $100 \mu \mathrm{m}$ (Figure 1). Although the micrograph of only one sample is shown, the morphology and ${ }_{95}$ particle size distribution of all materials are very similar. According to elemental analysis, the amount of $\mathrm{S}$ in the samples varied from as high as $\sim 8.5 \mathrm{wt} . \%(\sim 3$ at. $\%)$ in the AC-600 sample to $3.4 \mathrm{wt} \%(\sim 1.3$ at. $\%)$ in the AC-800 sample and $2.5 \mathrm{wt}$. $\%(\sim 1$ at. \%) AC-850 sample. The $\mathrm{S} \%$ in pure PTh is 28.2 wt. \% $100(\sim 9$ at. $\%)$, which is much higher than that in any material produced because part of $\mathrm{S}$ is lost in the form of $\mathrm{SO}_{2}$ and $\mathrm{CS}_{2}$ during carbonization and activation steps.

TEM characterization provided more insights into the effect of synthesis (activation) temperature on the microstructure of the 05 produced ACs. While all the produced samples demonstrated uniform and highly disordered microstructure, higher synthesis temperature resulted in slightly larger and less curved graphene segments (Figure 2), suggesting a lower concentration of structural defects. This can be more clearly seen near the outer 110 surface of the particles, where smaller sample thickness resulted in less overlap between the randomly oriented graphene layers. The variations in the TEM sample thickness combined with the lack of an order (alignment) within the carbon pores and the resulting pore overlap in the transmission imaging mode does not 
allow one to use TEM for visualizing variations in the pore size. Therefore, gas sorption measurements were utilized to get a precise evaluation of specific surface area (SSA) and pore size distributions (PSD) of the produced AC samples.

The shape of nitrogen $\left(\mathrm{N}_{2}\right)$ sorption isotherms (Figure 3a) provides us insights about the porosity of the samples. The $\mathrm{N}_{2}$ uptake at low relative pressures $\left(\mathrm{P} / \mathrm{P}_{0}<0.1\right)$ indicates the relative volume of the micropores. ${ }^{60}$ Therefore, one would expect the smallest volume of micropores (pores $<2 \mathrm{~nm}$ ) in the sample 10 produced at the lowest synthesis temperature, i.e. $600{ }^{\circ} \mathrm{C}$, whereas for higher activation temperatures, $800-850{ }^{\circ} \mathrm{C}$, the volume of micropores would be larger and similar. The increase in the $\mathrm{N}_{2}$ uptake with the activation temperature up to $\mathrm{P} / \mathrm{P}_{0} \sim 0.5-0.6$ for $850{ }^{\circ} \mathrm{C}$ is indicative of the generation of mesopores. ${ }^{60}$ Indeed, as

15 the activation temperature rises, an enlargement of the size and population of mesopores is observed (see Figure $3 \mathbf{b}$ ). The sample produced at $600{ }^{\circ} \mathrm{C}$ exhibits the lowest volume of micropores (with a size centred at $\sim 1.1 \mathrm{~nm}$ ) and virtually no mesopores. In contrast, the samples produced at higher activation temperatures 20 show similar pore size distributions (PSDs) below $2 \mathrm{~nm}$, but increasing volume of mesopores $(>2 \mathrm{~nm})$ with the activation temperature. The pore volume of the samples increases steadily with the synthesis temperature, whereas the SSA reaches its highest value for $800^{\circ} \mathrm{C}$ (i.e. $3000 \mathrm{~m}^{2} \mathrm{~g}^{-1}$ ) (inset in Figure 3a).

${ }_{25}$ Remarkably, all the samples possess large SSA in the range between 1800 and $3000 \mathrm{~m}^{2} \mathrm{~g}^{-1}$, which is important for EC applications.

The surface chemical properties of the produced materials were examined by X-ray Photoelectron Spectroscopy (XPS). 30 Interestingly, in comparison to the elemental analysis measurements, XPS studies showed similar S contents for AC800 and AC- 850 but nearly 1.5 times higher S content in AC-600 sample. This suggests a uniform distribution of $\mathrm{S}$ along the particles for the samples synthesized at higher temperatures,

35 whereas for the lowest activation temperature, the amount of $\mathrm{S}$ is higher in the surface than in the core of the particles. Figure 4 shows the $C_{1 s}$ and $S_{2 p}$ core level spectra of all tested samples. Two regions can be identified in the $\mathrm{C}$ 1s spectrum: (a) a region at $282-286 \mathrm{eV}$, which can be de-convoluted into two peaks at $40284.3 \mathrm{eV}$ and $285.1 \mathrm{eV}$, attributed to sp2 and $\mathrm{C}-\mathrm{H}$ bonding, respectively; and (b) a broad shoulder at $286-292 \mathrm{eV}$. This region represents an overlap of several peaks with similar intensities, including $286.5 \mathrm{eV}(\mathrm{C}=\mathrm{O}), 287.2 \mathrm{eV}(\mathrm{C}-\mathrm{O}$ and C-S), $289.1 \mathrm{eV}$ ($\mathrm{CO}_{2-}$ ) and $291.2 \mathrm{eV}$ (shape-up satellite due to $\pi-\pi^{*}$ transition in 45 aromatic rings). Because of the relatively low intensity of this shoulder, high full width at half maximum (FWHM) of all the potentially contributing peaks and possible variations in the position of each of these peaks, the quantitative analysis of the contributions of various functional groups to the XPS spectra ${ }_{50}$ becomes challenging and prone to errors. In contrast, analysis of the $\mathrm{S}_{2 \mathrm{p}}$ spectra is more straightforward. It consists of two doublets: a lower energy doublet at 164.0 and $165.3 \mathrm{eV}$, attributed to sulfide groups (such as -C-S-C- bridges), and a higher energy doublet at 168.6 and $170.1 \mathrm{eV}$, which can be ${ }_{55}$ assigned to sulfone bridges (-C-SO $\left.{ }_{2}-\mathrm{C}-\right)$. It can be seen that the contribution of sulfone bridges increases with the decrease of the activation temperature (Figure $4 \mathrm{~b}$ ). Those sulfone bridges form as a consequence of the oxidizing conditions present during the chemical activation process. ${ }^{[18]}$

Raman spectroscopy reveals the effect of synthesis conditions on the changes in the average microstructure of the produced ACs. In Raman spectra of carbon based materials (Figure 5), G band located at $1583 \mathrm{~cm}^{-1}$ is attributed to in-plane $\mathrm{sp}^{2} \mathrm{C}-\mathrm{C}$ bond vibrations, as in planar graphite. The additional disorder-induced ${ }_{65} \mathrm{D}$ band, forbidden in a perfect graphite by its symmetry and located at around $\sim 1350 \mathrm{~cm}^{-1}$, is currently believed to be linked to a double-resonance Raman process ${ }_{2}{ }^{61,62}$ when any phonon mode irrespective of the symmetry can give rise to this peak if the wave vector of the phonon is twice as large as the wave vector of the 70 electronic transition excited by the incident phonon. The ratio of the integrated intensities of a the disorder-induced $\mathrm{D}$ band and graphite $G$ band $\left(I_{D} / I_{G}\right)$ is related to the number of defects in the structure. ${ }^{61,} 62$ Figure $5 \mathbf{b}$ shows decrease of $\mathrm{I}_{\mathrm{D}} / \mathrm{I}_{\mathrm{G}}$ ratio monotonically with synthesis temperature, suggesting that faster 75 atomic diffusion at elevated temperatures allows for the local restructuring of carbon atoms and formation of larger graphitic segments and the reduced number of defects. A slow decrease of the full-width at half-maximum (FWHM) of the D-band at higher temperatures (Figure 5c) similarly suggests an increase in $\mathrm{C}$ 80 ordering within the AC samples. These results correlate well with previously discussed high-resolution TEM observations (Figure 2).

\subsection{Electrochemical performance of S-doped activated carbons}

Cyclic voltammetry (CV) studies performed on AC samples in different electrolytes reveal both the electrolyte ions - carbon interactions as well as the impact of the pore structure, ion chemistry and ion size on the transport and adsorption of ions within the carbon micro- and small meso- pores. We have 90 selected three different electrolytes for our studies: $\mathrm{LiCl}(6 \mathrm{M})$, $\mathrm{HCl}(1 \mathrm{M})$ and $\mathrm{H}_{2} \mathrm{SO}_{4}(0.5 \mathrm{M})$ aqueous solutions. The use of $\mathrm{LiCl}$ was motivated by its $\mathrm{pH}$ neutrality. The employ of $\mathrm{HCl}$ allows the examination of the impact of the substitution of $\mathrm{Li}^{+}$by $\mathrm{H}^{+}$. The lower molar concentration of the $\mathrm{HCl}$ solution was selected to 95 mitigate the potential $\mathrm{AC}$ oxidation at higher applied potentials. The $0.5 \mathrm{M} \mathrm{H}_{2} \mathrm{SO}_{4}$ electrolyte was selected due to its common industrial applications. In addition, we were interested in revealing the effect that bulky anions_(such as $\mathrm{HSO}_{4}{ }^{-}$and $\mathrm{SO}_{4}{ }^{2-}$, in a simplistic case) may have on the ion transport rate in our 100 carbon materials, in which we aimed to eliminate the smallest micropores.

Figure 6 shows representative $\mathrm{CV}$ behavior of AC-800 sample in these electrolyte solutions in a symmetric cell. The CV curves of this carbon materials in a $\mathrm{pH}$-neutral $\mathrm{LiCl}$ electrolyte 05 exhibits a perfect rectangular shape with no pseudocapacitive peaks visible and with nearly constant capacitance for the range of sweep rates (Figure 6a). Increasing the sweep rates from 1 to over $50 \mathrm{mV} \cdot \mathrm{s}^{-1}$ only affected the transient regions where the current direction was abruptly inversed (top left and bottom right 110 portion of the curves) and high ionic fluxes within both the very thick $(>200 \mu \mathrm{m})$ electrodes and the very large $(10-100 \mu \mathrm{m})$ individual porous carbon particles were necessitated. However, after this transient period the specific capacitance was nearly unaffected by increasing the sweep rate. This suggests that the 15 accessibility of the internal micropores to electrolyte ions was excellent and that little-to-no bottle-neck pores could obstruct the 
ions from reaching all the inner surface area even at such a high (for thick electrodes / large particles) sweep rates.

Interestingly, when switching to an $\mathrm{HCl}$ solution the $\mathrm{CV}$ curves changed markedly (Figure 6b). First, we observe an 5 abrupt increase of the current when approaching higher voltages (near $\pm 0.6 \mathrm{~V}$ ), suggesting oxidation reactions and possibly some electrolyte decomposition. This can be seen particularly clearly at the slowest sweep rate of $1 \mathrm{mV} \cdot \mathrm{s}^{-1}$. Second, we observe noticeably smaller capacitance (continuous decrease in current in 10 the linear region from $-0.3 \mathrm{~V}$ to $0.3 \mathrm{~V}$ ) at higher sweep rates. Since the size of the $\mathrm{H}^{+}$ions in both the de-solvated state $(0.035$ and $0.09 \mathrm{~nm}$, respectively) and the solvated state is smaller than that of the $\mathrm{Li}^{+}(0.28$ and $0.34 \mathrm{~nm}$, respectively), the total device capacitance cannot be negatively affected by the replacement of ${ }_{15} \mathrm{Li}^{+}$by smaller $\mathrm{H}^{+}$. Furthermore, since the size of the solvated $\mathrm{H}^{+}$ is much smaller than $\mathrm{Li}^{+}$, we shall expect ionic accessibility of the internal micropores to be better for $\mathrm{H}^{+}$. In contrast, we clearly observe lowering capacitance at faster sweep rates in the case of $1 \mathrm{M} \mathrm{HCl}$ electrolyte, as deduced by comparing Figures $\mathbf{6 a}$ and $\mathbf{b}$.

20 Higher molarities of $\mathrm{HCl}$ results in even stronger sweep-rate dependence. The above results suggest that the inferior capacitance retention with increasing sweep rates of $1 \mathrm{M} \mathrm{HCl}$ electrolyte is largely related to the slower pseudocapacitance redox reactions between the carbon functional groups and acidic 25 electrolyte. The interactions of the ion solvated shells with polar functional groups may, in principle, further slow down the ion transport within porous carbon. ${ }^{11}$ However, we observe similar capacitance decrease at higher sweep rates in the transient regions (after abruptly inversed current direction, compare Figure 6a and $30 \mathrm{~b}$ ), suggesting that the resistance faced by electrolyte ions traveling within the carbon pores remained similar. The addition of pseudocapacitance shall result in the increase in the maximumachievable total capacitance, which we indeed observe. At the same time, at a higher rate $\left(50 \mathrm{mV} \cdot \mathrm{s}^{-1}\right)$ (when redox reactions 35 have insufficient time to proceed) the capacitance in both electrolytes is very similar. The combined effect of slightly larger anion size and slightly higher strength of the $0.5 \mathrm{M} \mathrm{H}_{2} \mathrm{SO}_{4}$ electrolyte solution results in marginally slower rate capability and slightly higher pseudocapacitance contribution (compare

${ }_{40}$ Figure 6c and b). In both cases, however, we propose that the degree of the decrease in the specific capacitance with increasing sweep rates may serve as simple tool for the rough estimation of the pseudocapacitance contribution. We shall note, though, that such capacitance shall be measured at a voltage (in the case of a 45 symmetric cell) sufficiently far away from the transient current range (in our case, away from $-0.6 \mathrm{~V}$ for the positive current loop of the $\mathrm{CV}$ or away from the $+0.6 \mathrm{~V}$ for the negative current loop of the $\mathrm{CV}$ ) so that the ion transport rate within the carbon microand meso- pores is sufficiently fast to allow the double-layer to

${ }_{50}$ be established and the current/capacitance plateau to be reached at the highest sweep rate. A similar strategy can be used for the pseudocapacitance estimation from the differential capacity curves of the charge-discharge tests, when recorded at different current densities.

In order to assess the effect of the AC synthesis conditions on the EC performance we compare the $\mathrm{CV}$ graphs of AC-600 and $\mathrm{AC}-850$ in $6 \mathrm{M} \mathrm{LiCl}$ (Figure $7 \mathbf{a}$ and b). The $\mathrm{pH}$ neutral electrolyte minimizes oxidation reactions at higher voltages, which could mask the AC properties. The AC-600 synthesized at 60 the lowest temperature and containing sulfone groups (Figure 4) exhibits quite poor performance. It has a distinguished redox peak near $0 \mathrm{~V}$ and a visible oxidation process when EC is approaching $0.6 \mathrm{~V}$ (Figure 7a). In spite of its high specific surface area (Figure 3a), the value of the specific capacitance is rather small ${ }_{65}$ and indicates that a portion of the surface area was not accessible by electrolyte ions even at the slowest rate. More importantly, the $\mathrm{CV}$ curves for this sample show a high slope (a higher current at higher voltage), which indicates a significant leakage current (Figure 8). Increasing the temperature to 800 (Figure 6a) or 850 $70{ }^{\circ} \mathrm{C}$ (Figure 7b) virtually eliminates both the pseudocapacitance contributions and the leakage current (Figure 8c). Both samples perform almost as an ideal EDLC for all the sweep rates under study). This indicates that the sulfur present in these high temperature carbons ( $\sim 1-1.3$ at. \%) is electrochemically inactive 75 in $\mathrm{LiCl}$ and does not induce leakage, which is an important finding for this S-containing AC technology. To further illustrate the role of sulfide bridges in improving ion transport and increasing the electrochemically accessible surface area, a typical non-S-doped activated carbon with $\sim 40 \%$ lower surface area and 80 broad pore size distribution (some pores up to $3 \mathrm{~nm}$ ) was made into electrodes with the same thickness and mass loading and then characterized by $\mathrm{CV}$. We observe that its capacitance is over 4 times smaller and its rate capability is inferior (compare Figure 7c with 6a and 7b). Such electrochemical tests indicate that 85 introduction of sulfide bridges may serve as an effective route to depress the shrinkage of the smallest pores to afford rapid ion transport without inducing unwanted redox reactions.

Another important observation is that for almost all the tested samples equivalent leakage resistance was the highest in a $\mathrm{pH}$ 90 neutral $\mathrm{LiCl}$ electrolyte (this corresponds to the lowest leakage current) and the lowest (highest leakage current) in a strong acidic $\mathrm{H}_{2} \mathrm{SO}_{4}$ electrolyte (Figure 8). Furthermore, we found a positive correlation between the parasitic leakage currents observed in some devices (see Figure 8c) and the ${ }_{95}$ pseudocapacitance contribution estimated from the capacitance retention measurements (Figure 9). This result serves as evidence that many redox-active functional groups contribute to the selfdischarge of EDLCs and shall be avoided.

We propose that the presence of acidic functional groups 100 participating in the pseudocapacitive reactions reduce the local $p H$ in their proximity. This should trigger hydrogen generation at a negative electrode even at the potentials where $\mathrm{H}_{2} \mathrm{O}$ is thermodynamically stable in a neutral (e.g. $\mathrm{LiCl}$ ) electrolyte solution. The use of acidic electrolytes $\left(\mathrm{HCl}\right.$ and $\mathrm{H}_{2} \mathrm{SO}_{4}$ 105 solutions) further enhances the hydrogen generation at the anode. Indeed, according to a Pourbaix diagram, water is prone to decomposition and hydrogen generation at a low $\mathrm{pH}$ according to:

\section{$2 \mathrm{H}_{2} \mathrm{O}+2 \mathrm{a}^{-} \rightarrow \mathrm{H}_{2} \uparrow+2 \mathrm{OH}^{-}$}

110 The electrons needed to sustain such reactions are taken from the charge stored within the carbon negative electrode. This decrease in the total charge leads to the release of a portion of the adsorbed ions constituting the double layer of this electrode in order to maintain the local charge equilibrium. This, in turn, 115 raises the potential of the negative electrode and contributes to the self-discharge. A possible presence of basic functional groups 
on the carbon surface of a positive electrode may similarly induce the generation of oxygen in their facility, consuming holes and lowering the cathode potential during storage. Oxidation of carbon cathode in the proximity of defects and functional groups 5 may additionally lead to the generation of $\mathrm{CO}$ and $\mathrm{CO}_{2}$. All of the described reactions may contribute to a leakage current and selfdischarge of an EDLC.

The sulfur functionalities may contribute to pseudocapacitance by redox reactions involving sulfone groups.

10 The proposed reactions are listed below. As the first step, some of the sulfone groups are reduced into sulfoxide groups (reaction 2). Sulfoxide groups are then reduced into sulfenic acid, which is reversible (reaction 3). A fraction of sulfenic acid can be ionized and adsorb positively charged protons or $\mathrm{Li}^{+}$(reactions 4 and 5).

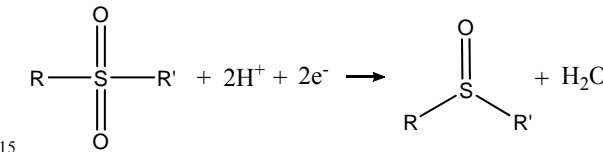<smiles>[R][SH]([R])O</smiles>

$$
\|_{\mathrm{R}_{\mathrm{R}^{\prime}}}^{\mathrm{O}}+\mathrm{H}^{+}+\mathrm{e}^{-} \rightleftarrows \mathrm{R}_{\mathrm{R}^{\prime}}^{\mathrm{O}}+\mathrm{Li}^{+}+\mathrm{e}^{-}
$$

In addition to $\mathrm{S}$, the tested materials, particularly those 20 synthesized at a low temperature, contain different oxygen functionalities. Furthermore, acidic electrolytes, especially $\mathrm{H}_{2} \mathrm{SO}_{4}$, tend to slightly oxidize the carbon electrode and induce oxygen-containing functional groups. Such functionalities are known to be involved in redox reactions and contribute to 25 pseudocapacitance. In an example of a quinone functional group, the redox reaction may proceed as following (Reaction 6):<smiles>O=C1C=CC(=O)C=C1</smiles>

Figure 10 summarizes the changes in the integrated capacitance of S-doped AC electrodes in three types of 30 electrolytes. All tested materials show higher capacitances in acid solutions due to the pseudocapacitance contribution. On the other hand, the capacitance retentions are better in a $\mathrm{pH}$ neutral $\mathrm{LiCl}$ solution since the redox reactions contributing to pseudocapacitance are slower than double layer formation. The 35 rapid ion transport in AC-800 and AC-850 samples due to their relatively large pore size (Figure 3 ) and the lack of slow redox reactions leads to excellent capacitance retention. The strongly improved performance of AC-600 in acidic solution may be also result of its in-situ surface chemistry modification and thus 40 improved electrolyte wetting (compare its performance in Figure 10a with that in Figure 10b and c).

Galvanic charge-discharge (C-D) tests performed at different current densities compliments $\mathrm{CV}$ tests and reveal largely similar trends (Figure 11): AC-800 and AC-850 possess both higher 45 capacitances and higher capacitance retention than AC-600 sample. All electrodes show the highest capacitances in acidic electrolytes and the highest capacitance retention in a $\mathrm{pH}$-neutral $6 \mathrm{M} \mathrm{LiCl}$ solution, except for AC-600. This behavior can be explained by restricted accessibility to the porosity, slow redox 50 reactions and high leakage current in $6 \mathrm{M} \mathrm{LiCl}$ electrolyte.

The voltage profiles of the AC- 850 sample in $6 \mathrm{M} \mathrm{LiCl}$ and $0.5 \mathrm{M} \mathrm{H}_{2} \mathrm{SO}_{4}$ in C-D test are shown in Figure 12a-c. The constant slopes of most of the graphs are the typical for double layer capacitors, but cannot guarantee the lack of pseudocapacitance 55 contributions, as previously discussed. The deviations from the linear curves, however, indicate redox activity (Figure 12c and d). The lack of IR drop in the AC-850 sample demonstrates a low device resistance. The AC-600 sample, in contrast, exhibits both severe distortions from the linearity of the curves (likely related 60 to the pseudocapacitance reactions previously discussed) and high IR drop even at a very moderate current density of $50 \mathrm{~mA} \cdot \mathrm{g}^{-}$ 1 (likely related to the slow electrolyte transport caused by the interaction of its original functional groups with electrolyte solvent).

65 To further investigate the presence of pseudocapacitance in highly functionalized samples, EIS characterization was performed. Shown in Figure 13 are the Nyquist plots of sample AC-850 (Figure 13a) and AC-600 (Figure 13b) respectively in $6 \mathrm{M} \mathrm{LiCl}, 1 \mathrm{M} \mathrm{HCl}$ and $0.5 \mathrm{M} \mathrm{H}_{2} \mathrm{SO}_{4}$. Nyquist plots of AC-850 do 70 not show any semicircles in electrolytes. On the contrary, plots of AC-600 show clear semicircles associated with the charge transfer processes, and these semicircles are larger for samples with higher pseudocapacitance.

The changes in the phase angle vs. frequency are shown in 75 Figure 14. While the AC-850 sample shows the angle close to $90^{\circ}$ (phase change $=0^{\circ}$ ) for low frequency as an ideal capacitor, the AC-600 sample shows significant deviations from the ideal behavior. When comparing performance of AC-850 in different electrolytes, we observe that $\mathrm{H}_{2} \mathrm{SO}_{4}$ electrolyte, which introduces 80 some pseudocapacitance, shows slower frequency response and larger time constant. In a $\mathrm{pH}$ neutral $\mathrm{HCl}$ electrolyte the time constant is the smallest in both samples. In case of the AC-600 sample, this may indicate favorable interactions of the initially present functional groups in AC-600 with this electrolyte that ${ }_{85}$ favors better access of electrolyte ions to the carbon surface.

\section{Summary and conclusions}

The intrinsic sulfur (S) - doping of activated carbon (AC) by carbonization of S-based polymers may be an efficient route to synthesize porous carbon for applications in EDLC electrodes 90 with high rate capability and low leakage. The sulfide bridges present in the polymer precursors are proposed to resist the pore shrinkage during activation and reduce the amount of bottle-neck pores.

The ACs produced by carbonization and simultaneous 95 activation of polythiophene show disordered carbon microstructure and specific surface area in the range $\sim 1800-3000$ $\mathrm{m}^{2} \mathrm{~g}^{-1}$. Increasing synthesis temperature results in the enlargement of the pore size, as well as the reduction in the concentration of defects and sulfone functional groups. Synthesis temperatures of 
$\sim 800{ }^{\circ} \mathrm{C}$ or higher were found to be required to achieve the desired S-doped AC characteristics in EDLC applications. In spite of the sulfur remaining in the samples produced at $800-850$ ${ }^{\circ} \mathrm{C}$, they demonstrated little, if any, pseudocapacitance, excellent 5 rate capabilities and low leakage currents when tested in symmetric EDLC devices with neutral aqueous electrolytes. In contrast, acidic aqueous electrolytes induced both the active redox reactions and significant leakage currents in EDLC devices.

10 We described the contribution of various functional groups to pseudocapacitance and observed a strong correlation between the carbon pseudocapacitance and the strongly undesirable device self-discharge during its operation. We proposed that the presence of functional groups participating in the 15 pseudocapacitive reactions changes the local $p H$ in their proximity and triggers electrolyte decomposition. This emphasizes the need to develop experimental techniques capable of estimating the pseudocapacitance contribution, even when cyclic voltammetry does not reveal any characteristics peaks. We

20 proposed for the first time a simple route to detect such a pseudocapacitance by harnessing the difference between the characteristic times required to establish a double layer in mesoporous carbons and that of the slower pseudocapacitive redox reactions. According to our method we measure the 25 difference in the total specific capacitances recorded at two sweep rates: (i) a sweep rate sufficiently slow for both double layer and pseudocapaciance to contribute to charge storage and (ii) a sweep rate too fast for the redox reactions to proceed, but still sufficiently slow for the double layer to be fully established. A 30 similar strategy can be used for the pseudocapacitance estimation from the differential capacity curves of the charge-discharge tests, when recorded at different current densities. In spite of its only semi-qualitative nature, the simplicity of this method shall allow it to become a valuable tool for a more comprehensive evaluation 35 of carbon electrode performance in ECs.

\section{Acknowledgements}

The financial support for this research work provided by the US Army Research Office (grant W911NF-12-1-0259), by the Spanish MINECO (CQT2011-24776 and MAT2012-31651) and 40 by the Energy Efficiency \& Resources program of the Korea Institute of Energy Technology Evaluation and Planning (KETEP) funded by the Korea government Ministry of Knowledge Economy (grant 20118510010030) is gratefully acknowledged. M. S. thanks the Spanish MINECO for the award 45 of a Ramón y Cajal contract.

\section{References}

1. F. B. Elzbieta Frackowiak, Carbon, 2001, 39.

2. R. Kotz, Electrochimica Acta, 2000, 45.

3. Y. G. Patrice Simon, Nature materials, 2008, 7.

50 4. C.-C. Hu, Electrochemistry Communications, 2002, 4

5. K. Zhang, L. L. Zhang, X. S. Zhao and J. Wu, Chemistry of Materials, 2010, 22, 1392-1401.

6. Y. Wang, The journal of physical chemistry C, 2009, 113.
7. T. Brousse, P.-L. Taberna, O. Crosnier, R. Dugas, P. Guillemet, Y. Scudeller, Y. Zhou, F. Favier, D. Bélanger and P. Simon, Journal of Power Sources, 2007, 173, 633-641.

8. A. Balducci, W. A. Henderson, M. Mastragostino, S. Passerini, P. Simon and F. Soavi, Electrochimica Acta, 2005, 50, 2233-2237.

9. S. W. Lee, N. Yabuuchi, B. M. Gallant, S. Chen, B.-S. Kim, P. T. Hammond and Y. Shao-Horn, Nature Nano, 2010, 5, 531-537.

10. W. Gu, N. Peters and G. Yushin, Carbon, 2012.

11. K. G. Gallagher, G. Yushin and T. F. Fuller, Journal of the Electrochemical Society, 2010, 157, B820-B830.

12. T. R. Jow and J. P. Zheng, Journal of the Electrochemical Society, 1998, 145, 49-52.

13. J. P. Zheng and T. R. Jow, Journal of the Electrochemical Society, 1995, 142, L6-L8.

14. H. Itai, H. Nishihara, T. Kogure and T. Kyotani, J. Am. Chem. Soc., 2011, 133, 1165-1167.

70 15. H. Nishihara, H. Itoi, T. Kogure, P. X. Hou, H. Touhara, F. Okino and T. Kyotani, Chemistry-a European Journal, 2009, 15, 53555363.

16. T. Kyotani, Z. X. Ma and A. Tomita, Carbon, 2003, 41, 1451-1459.

17. Z. X. Ma, T. Kyotani and A. Tomita, Chemical Communications, $752000,2365-2366$.

18. Y. Korenblit, A. Kajdos, W. C. West, M. C. Smart, E. J. Brandon, A. Kvit, J. Jagiello and G. Yushin, Advanced Functional Materials, 2012, 22, 1655-1662.

19. A. Kajdos, A. Kvit, F. Jones, J. Jagiello and G. Yushin, J. Am. Chem. Soc., 2010, 132, 3252.

20. C. Portet, Z. Yang, Y. Korenblit, Y. Gogotsi, R. Mokaya and G. Yushin, Journal of the Electrochemical Society, 2009, 156, A1-A6.

21. C. O. Ania, V. Khomenko, E. Raymundo-Pinero, J. B. Parra and F. Beguin, Advanced Functional Materials, 2007, 17, 1828-1836.

85 22. M. Rose, Y. Korenblit, E. Kockrick, L. Borchardt, M. Oschatz, S.

Kaskel and G. Yushin, in Small, 2011, vol. 7, pp. 1108-1117.

23. M. Oschatz, E. Kockrick, M. Rose, L. Borchardt, N. Klein, I. Senkovska, T. Freudenberg, Y. Korenblit, G. Yushin and S. Kaskel, Carbon, 2010, 48, 3987-3992.

90 24. Y. Korenblit, M. Rose, E. Kockrick, L. Borchardt, A. Kvit, S. Kaskel and G. Yushin, Acs Nano, 2010, 4, 1337-1344.

25. C. Vix-Guterl, E. Frackowiak, K. Jurewicz, M. Friebe, J. Parmentier and F. Beguin, Carbon, 2005, 43, 1293-1302.

26. J. Lee, J. Kim and T. Hyeon, Advanced Materials, 2006, 18, $2073-$ 952094.

27. L. Borchardt, M. Oschatz, M. Lohe, V. Presser, Y. Gogotsi and S. Kaskel, Carbon, 2012, 50, 3987-3994.

28. E. N. Hoffman, G. Yushin, T. El-Raghy, Y. Gogotsi and M. W. Barsoum, Microporous and Mesoporous Materials, 2008, 112, 526-532. 100 29. C. Portet, G. Yushin and Y. Gogotsi, J. Electrochem. Soc, 2008, 155 (7), A531-A536.

30. G. Yushin, A. Nikitin and Y. Gogotsi, in Nanomaterials Handbook, ed. Y. Gogotsi, CRC Press, 2006, pp. 239-282.

31. J. Chmiola, G. Yushin, Y. Gogotsi, C. Portet and P. Simon, Science, 105 2006, 313, 1760-1763.

32. J. Chmiola, G. Yushin, R. Dash and Y. Gogotsi, Journal of Power Sources, 2006, 158, 765-772.

33. M. Oschatz, L. Borchardt, M. Thommes, K. A. Cychosz, I. Senkovska, N. Klein, R. Frind, M. Leistner, V. Presser, Y. Gogotsi and 
S. Kaskel, Angewandte Chemie-International Edition, 2012, 51, 75777580 .

34. V. Presser, M. Heon and Y. Gogotsi, Advanced Functional Materials, 2011, 21, 810-833.

5 35. J. Eskusson, A. Janes, A. Kikas, L. Matisen and E. Lust, Journal of Power Sources, 2011, 196, 4109-4116.

36. H. Kurig, A. Janes and E. Lust, Journal of the Electrochemical Society, 2010, 157, A272-A279.

37. L. Permann, M. Latt, J. Leis and M. Arulepp, Electrochimica Acta, $10 \quad 2006, \mathbf{5 1}, 1274-1281$.

38. J. Leis, M. Arulepp, A. Kuura, M. Latt and E. Lust, Carbon, 2006, 44, 2122-2129.

39. A. Janes and E. Lust, Journal of the Electrochemical Society, 2006, 153, A113-A116.

15 40. G. Laudisio, R. K. Dash, J. P. Singer, G. Yushin, Y. Gogotsi and J. E. Fischer, Langmuir, 2006, 22, 8945-8950.

41. L. Wei and G. Yushin, Nano Energy, 2012, 1, 552-565.

42. L. Wei, M. Sevilla, A. B. Fuertes, R. Mokaya and G. Yushin, Advanced Functional Materials, 2012, 22, 827-834.

20 43. N.-S. Choi, Chen, Z., Freunberger, S.A., Ji, X., Sun, Y.-K., Amine, K., Yushin, G., Nazar, L.F., Cho, J., and Bruce, P.G., Angewandte Chemie International Edition, 2012, in press.

44. W. Gu, N. Peters and G. Yushin, Carbon.

45. E. Raymundo-Piñero, F. Leroux and F. Béguin, Advanced Materials, 25 2006, 18, 1877-1882.

46. L. Wei and G. Yushin, Carbon, 2011, 49, 4830-4838.

47. L. Wei and G. Yushin, Power Sources, 2011, 1964072 - 4079.

48. L. Wei, M. Sevilla, A. B. Fuertesc, R. Mokaya and G. Yushin, Advanced Energy Materials, 2011, 1, 356-361.

30 49. T. E. Rufford, D. Hulicova-Jurcakova, K. Khosla, Z. H. Zhu and G.

Q. Lu, Journal of Power Sources, 2010, 195, 912-918.

50. D. Hulicova-Jurcakova, M. Seredych, G. Q. Lu and T. J. Bandosz, Advanced Functional Materials, 2009, 19, 438-447.

51. D. Hulicova-Jurcakova, M. Kodama, S. Shiraishi, H. Hatori, Z. H.

35 Zhu and G. Q. Lu, Advanced Functional Materials, 2009, 19, 18001809.

52. E. Raymundo-Pinero, K. Kierzek, J. Machnikowski and F. Beguin, Carbon, 2006, 44, 2498-2507.

53. G. Salitra, A. Soffer, L. Eliad, Y. Cohen and D. Aurbach, Journal of 40 the Electrochemical Society, 2000, 147, 2486-2493.

54. L. Eliad, E. Pollak, N. Levy, G. Salitra, A. Soffer and D. Aurbach, Applied Physics a-Materials Science \& Processing, 2006, 82, 607613.

55. M. Arulepp, L. Permann, J. Leis, A. Perkson, K. Rumma, A. Janes

45 and E. Lust, Journal of Power Sources, 2004, 133, 320-328.

56. E. Lust, G. Nurk, A. Janes, M. Arulepp, P. Nigu, P. Moller, S. Kallip and V. Sammelselg, J. Solid State Electrochem., 2003, 7, 91-105.

57. G. Hasegawa, K. Kanamori, K. Nakanishi and T. Hanada, Carbon, 2010, 48, 1757-1766.

50 58. G. Hasegawa, M. Aoki, K. Kanamori, K. Nakanishi, T. Hanada and K. Tadanaga, Journal of Materials Chemistry, 2011, 21, 2060.

59. M. Sevilla and A. B. Fuertes, Microporous and Mesoporous Materials, 2012, 158, 318-323.

60. R. T. Yang, Adsorbents: Fundamentals and Applications, Wiley \&

55 Sons, Inc., Hoboken, NJ, USA, 2003.

61. C. Thomsen and S. Reich, Phys. Rev. Lett., 2000, 85, 5214-5217.
62. P. H. Tan, S. Dimovski and Y. Gogotsi, Phil. Trans. Royal Soc. A, 2004, 362. 


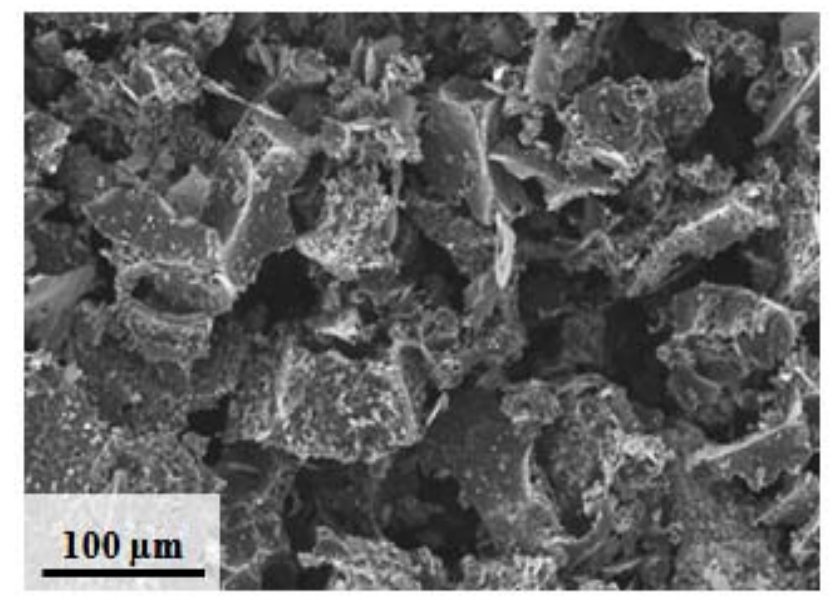

Figure 1. SEM micrograph of an activated carbon sample synthesized at $800^{\circ} \mathrm{C}$ (AC-800). 

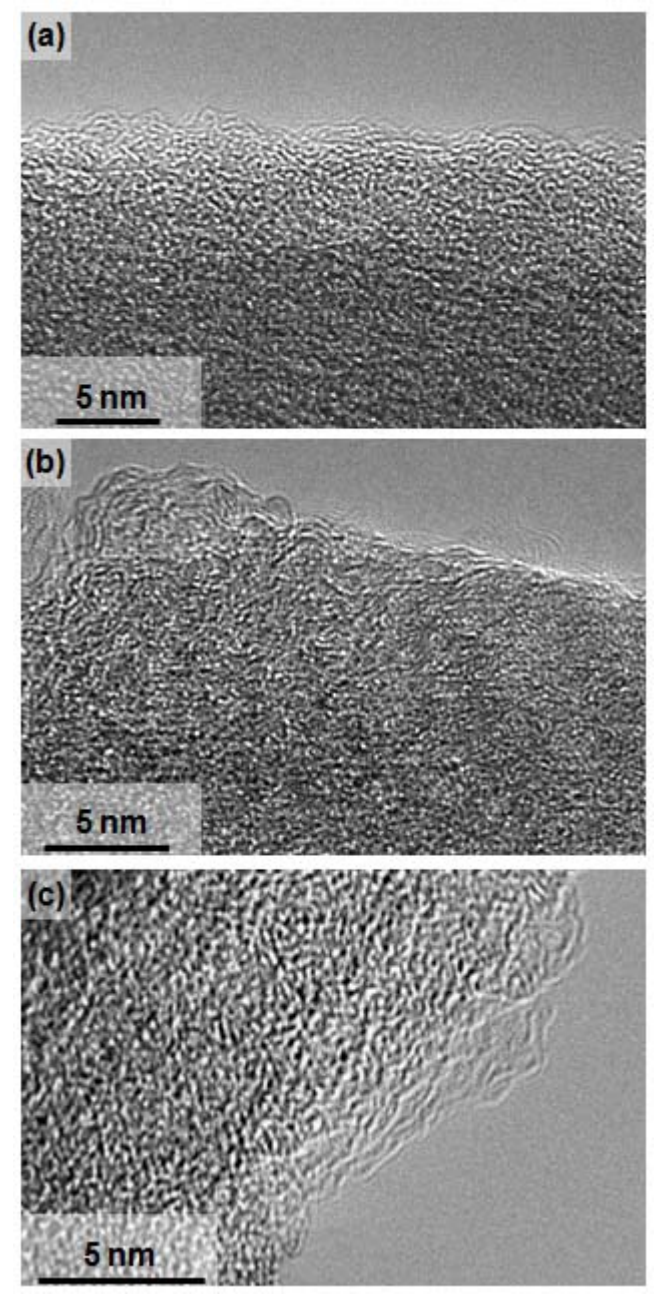

Figure 2. High-magnification TEM micrographs of activated carbon synthesized at (a) $600{ }^{\circ} \mathrm{C}$; (b) $800^{\circ} \mathrm{C}$ and (c) $850^{\circ} \mathrm{C}$. 

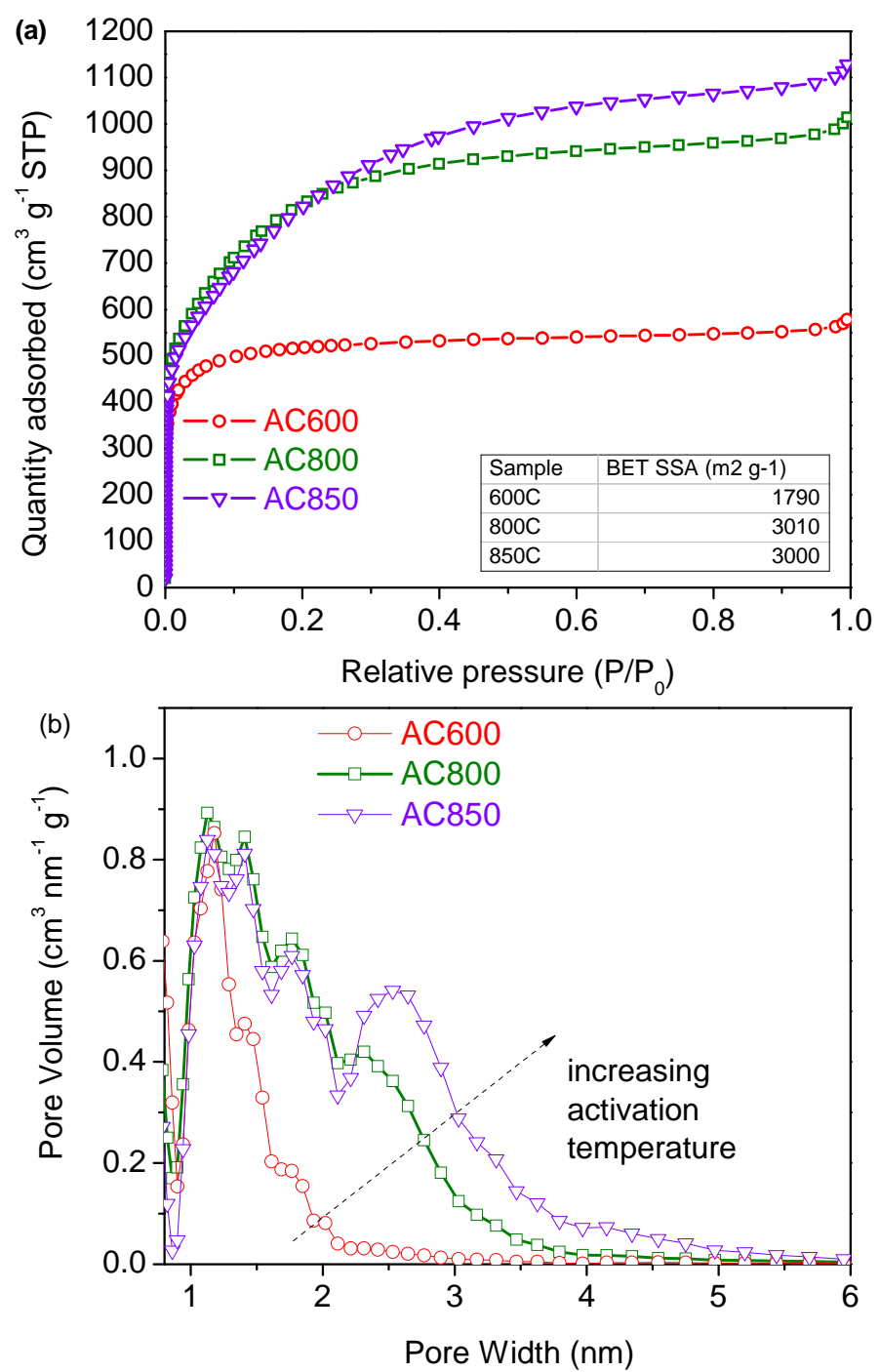

Figure 3. Porosity characterization of the S-containing activated carbon samples produced at four different temperatures: (a) $\mathrm{N}_{2}$ sorption isotherms collected at 77K and (b) DFT pore size distributions. 

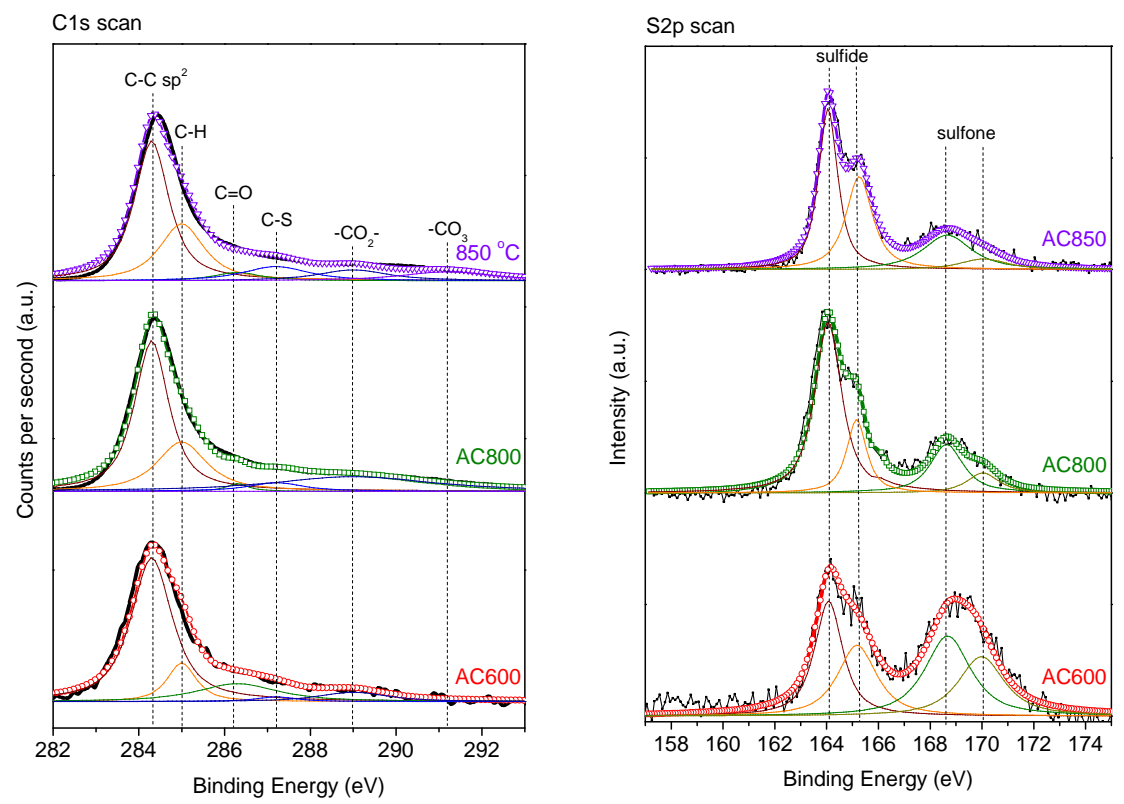

\begin{tabular}{|l|l|}
\hline Sample & S/C at. ratio \\
\hline AC-600 & 0.060 \\
\hline AC-800 & 0.015 \\
\hline AC-850 & 0.015 \\
\hline
\end{tabular}

Figure 4. XPS analysis of S-doped activated carbon materials: (a) C1s and (b) S2p core level spectra 

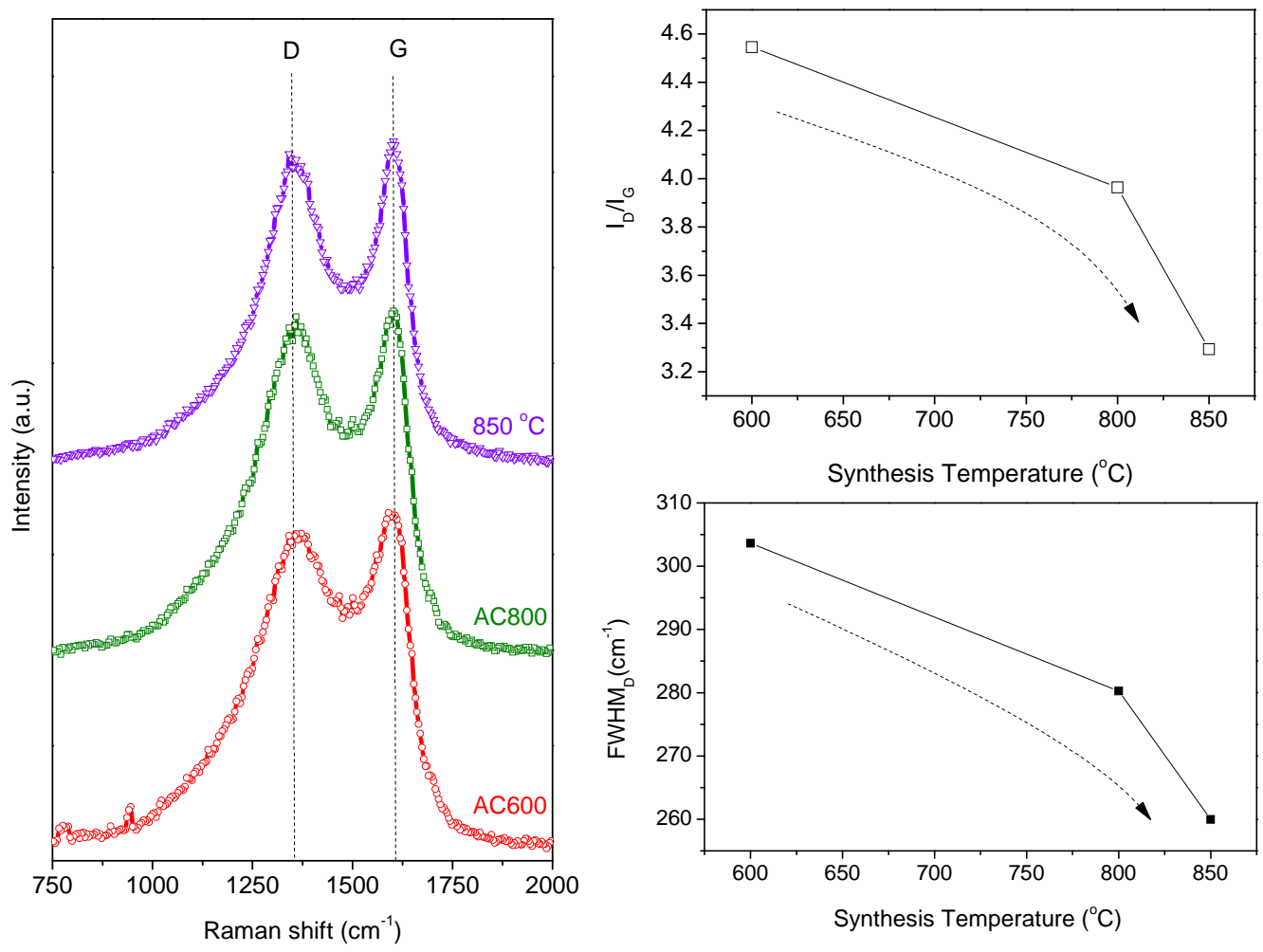

Figure 5. Raman spectroscopy of S-doped activated carbon materials: (a) Raman spectra, (b) the evolution of $I_{D} / I_{G}$ ratio and (c) FWHM of a D-band, respectively, with synthesis temperature. 

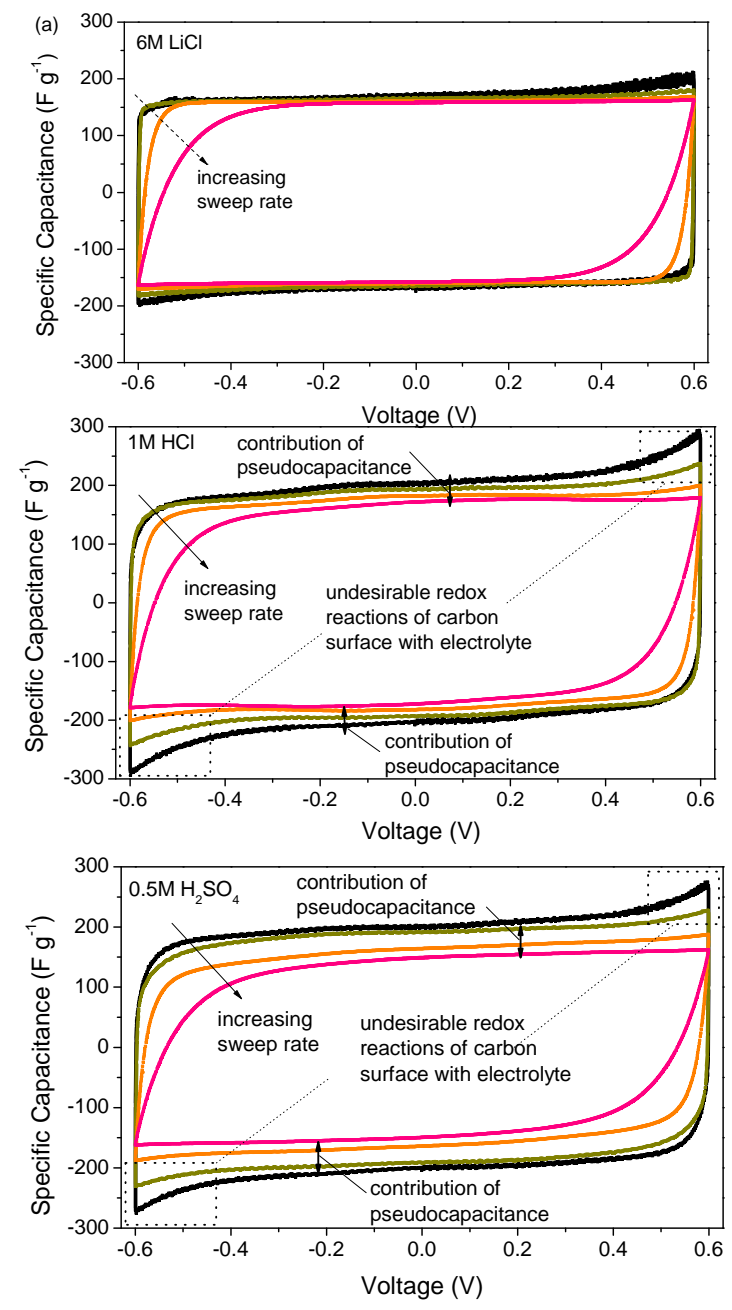

Figure 6. Cyclic voltammetry of AC-800 sample at the scan rates of $1,5,10$ and $50 \mathrm{mV} \cdot \mathrm{s}^{-1}$ in three different aqueous electrolytes: (a) $6 \mathrm{M} \mathrm{LiCl}$; (b) $1 \mathrm{M} \mathrm{HCl}$; (c) $0.5 \mathrm{M} \mathrm{H}_{2} \mathrm{SO}_{4}$. 

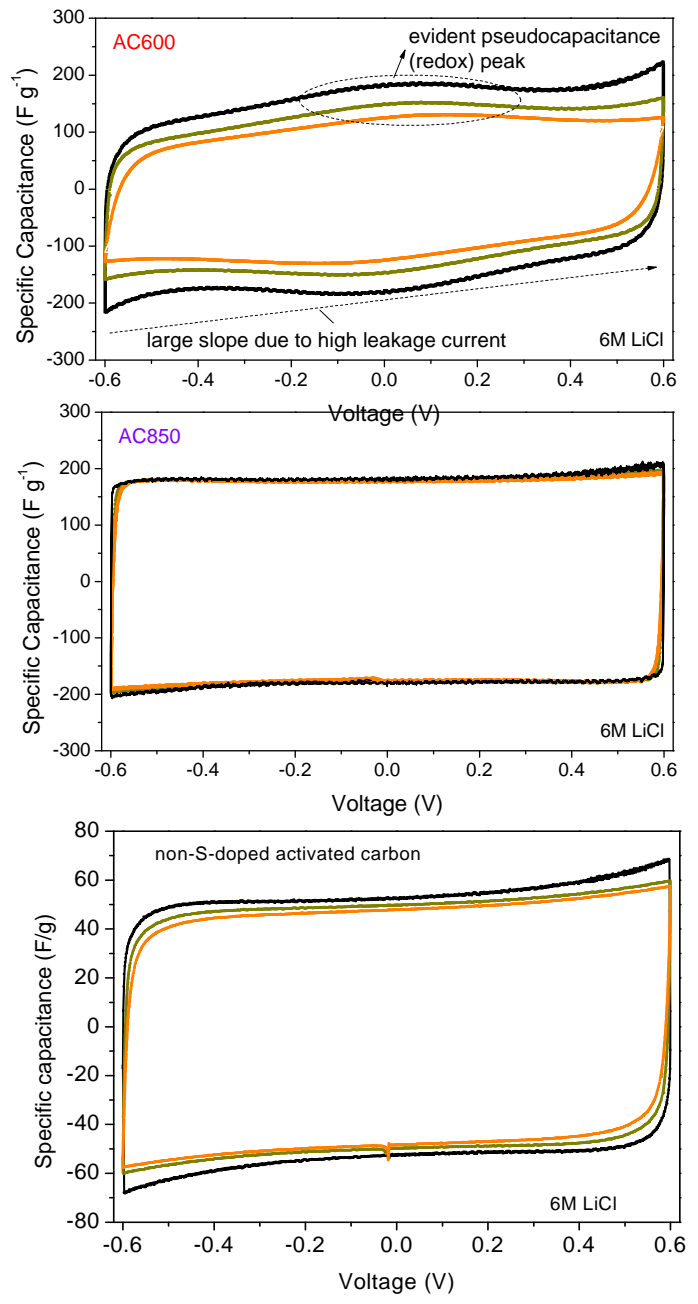

Figure 7. Cyclic voltammetry of AC samples synthesized at three different temperature: (a) AC600 and (b) AC850; and (c) mesoporous activated carbon with pores in the range of 0.5-4 $\mathrm{nm}$ but no $S$ doping. Beaker cells have been operated in $6 \mathrm{M} \mathrm{LiCl}$ aqueous solution. Presented data correspond to the sweep rates of 1,5 and $10 \mathrm{mV} \mathrm{s}^{-1}$. 

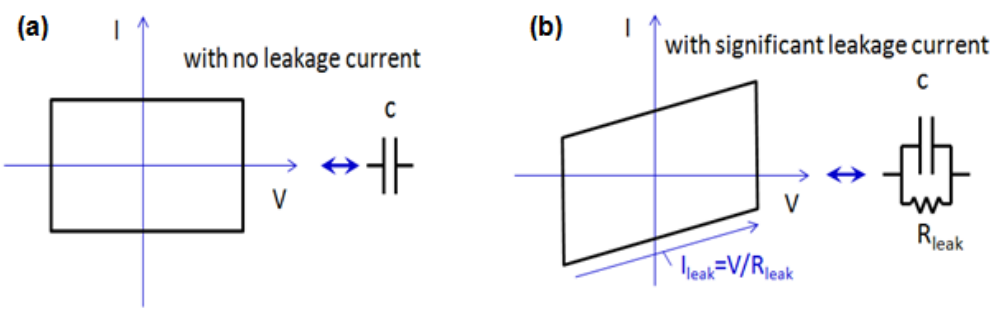

(c)

\begin{tabular}{|l|l|l|l|}
\hline & AC-600 & AC-800 & AC-850 \\
\hline $6 \mathrm{M} \mathrm{LiCl}$ & $4 \mathrm{kOhm} \cdot \mathrm{cm}^{2}$ & N/A & N/A \\
\hline $1 \mathrm{M} \mathrm{HCl}$ & $3.6 \mathrm{kOhm} \cdot \mathrm{cm}^{2}$ & $23 \mathrm{kOhm} \cdot \mathrm{cm}^{2}$ & N/A \\
\hline $0.5 \mathrm{M} \mathrm{H}_{2} \mathrm{SO}_{4}$ & $0.7 \mathrm{kOhm} \cdot \mathrm{cm}^{2}$ & $12 \mathrm{kOhm} \cdot \mathrm{cm}^{2}$ & $15 \mathrm{kOhm} \cdot \mathrm{cm}^{2}$ \\
\hline
\end{tabular}

Figure 8. Leak rate estimations. Schematic showing the cyclic voltammetry diagrams of idealized (infinitely fast with stable electrolyte) electrochemical capacitors (a) with no leakage current and (b) with significant leakage current and the equivalent circuits for these two conditions. (c) a table summarizing the leakage resistance measurements for each electrolyte and synthesized ACs. 


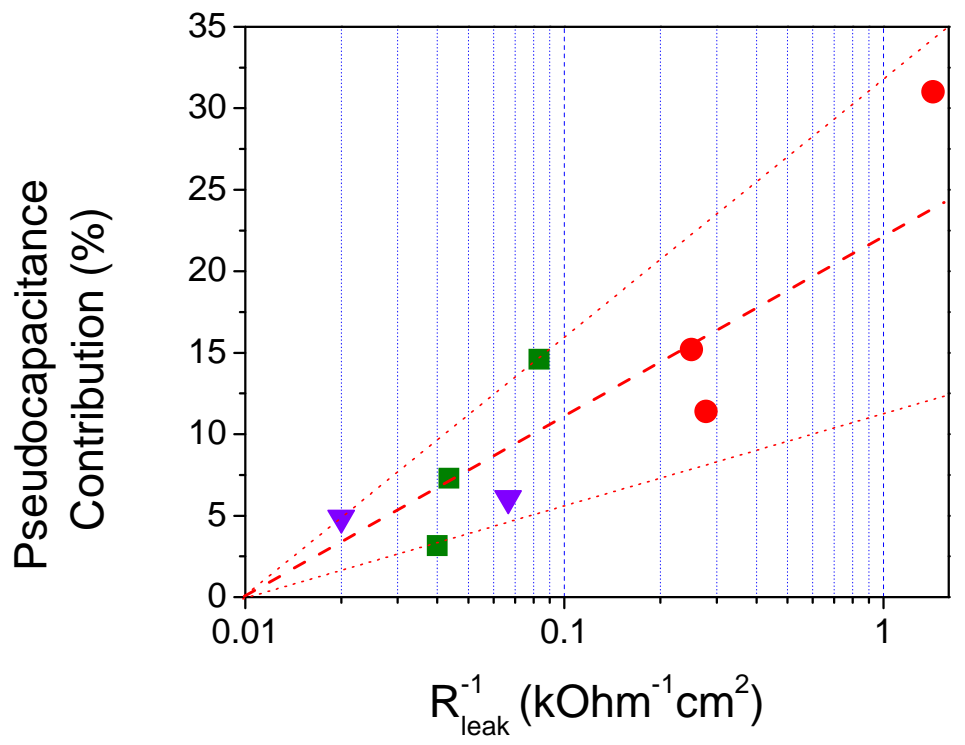

Figure 9. Pseudocapacitance of S-doped activated carbons AC600, AC800 and AC850 as a function of leakage conductance in different electrolytes. The pseudocapacitance was estimated from the difference between the currents measured at the potential sweeping rates of $1 \mathrm{mV} \mathrm{s}^{-1}$ and $10 \mathrm{mV} \mathrm{s}^{-1}$. The rate was sufficiently slow to allow double layer to be established. 

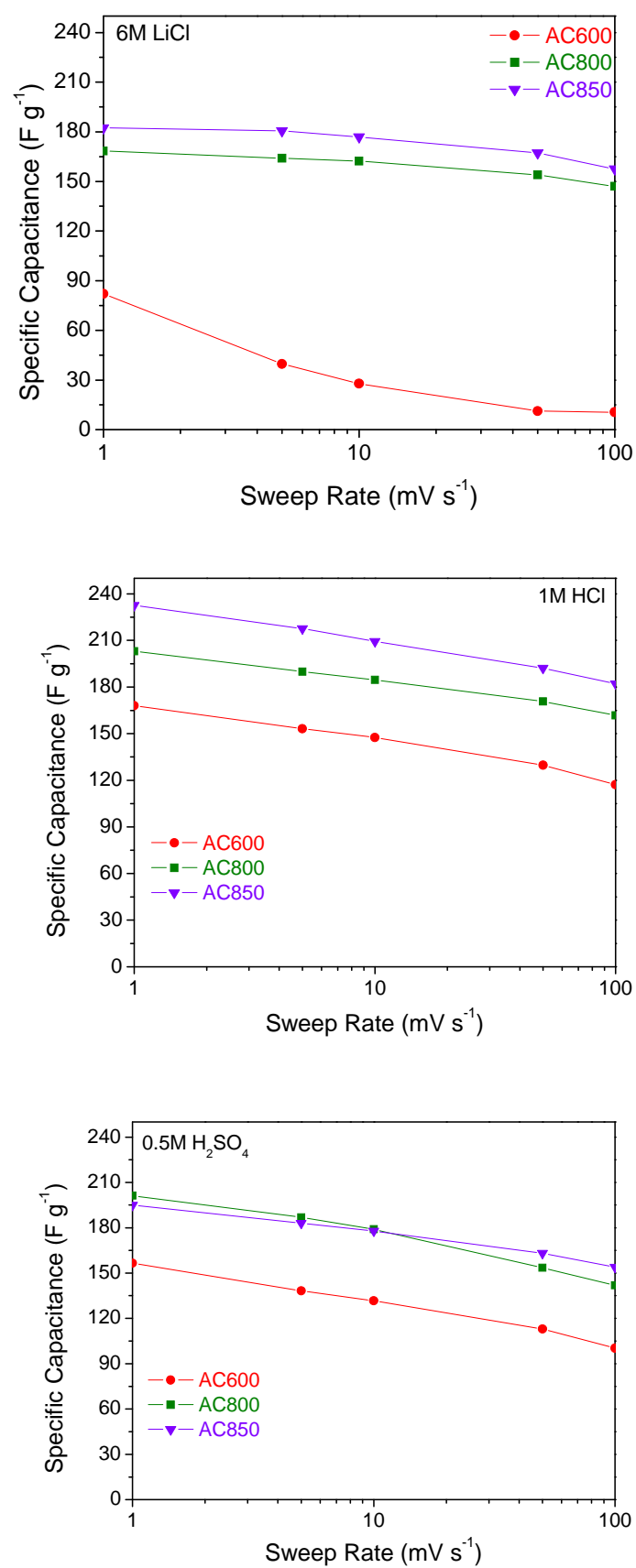

Figure 10. Specific capacitance retention of activated carbon samples produced at 600,800 and $8500^{\circ} \mathrm{C}$ as a function of sweep rate in three aqueous electrolytes: (a) $6 \mathrm{M} \mathrm{LiCl}$; (b) $1 \mathrm{M} \mathrm{HCl}$; (c) $0.5 \mathrm{M} \mathrm{H}_{2} \mathrm{SO}_{4}$. 

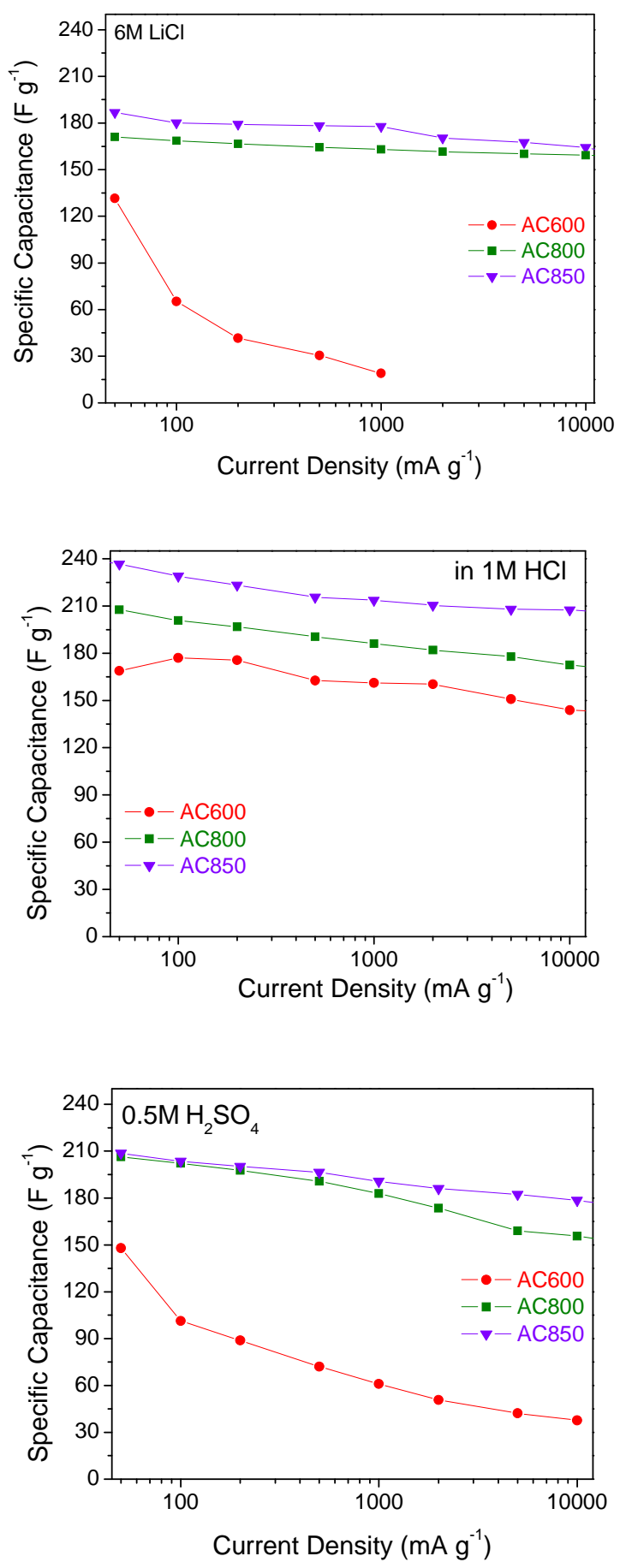

Figure 11. Specific capacitance retention of activated carbon samples produced at 600,800 and $850{ }^{\circ} \mathrm{C}$ as a function of current density in three aqueous electrolytes: (a) $6 \mathrm{M} \mathrm{LiCl}$; (b) $1 \mathrm{M} \mathrm{HCl}$; (c) $0.5 \mathrm{M} \mathrm{H}_{2} \mathrm{SO}_{4}$. 

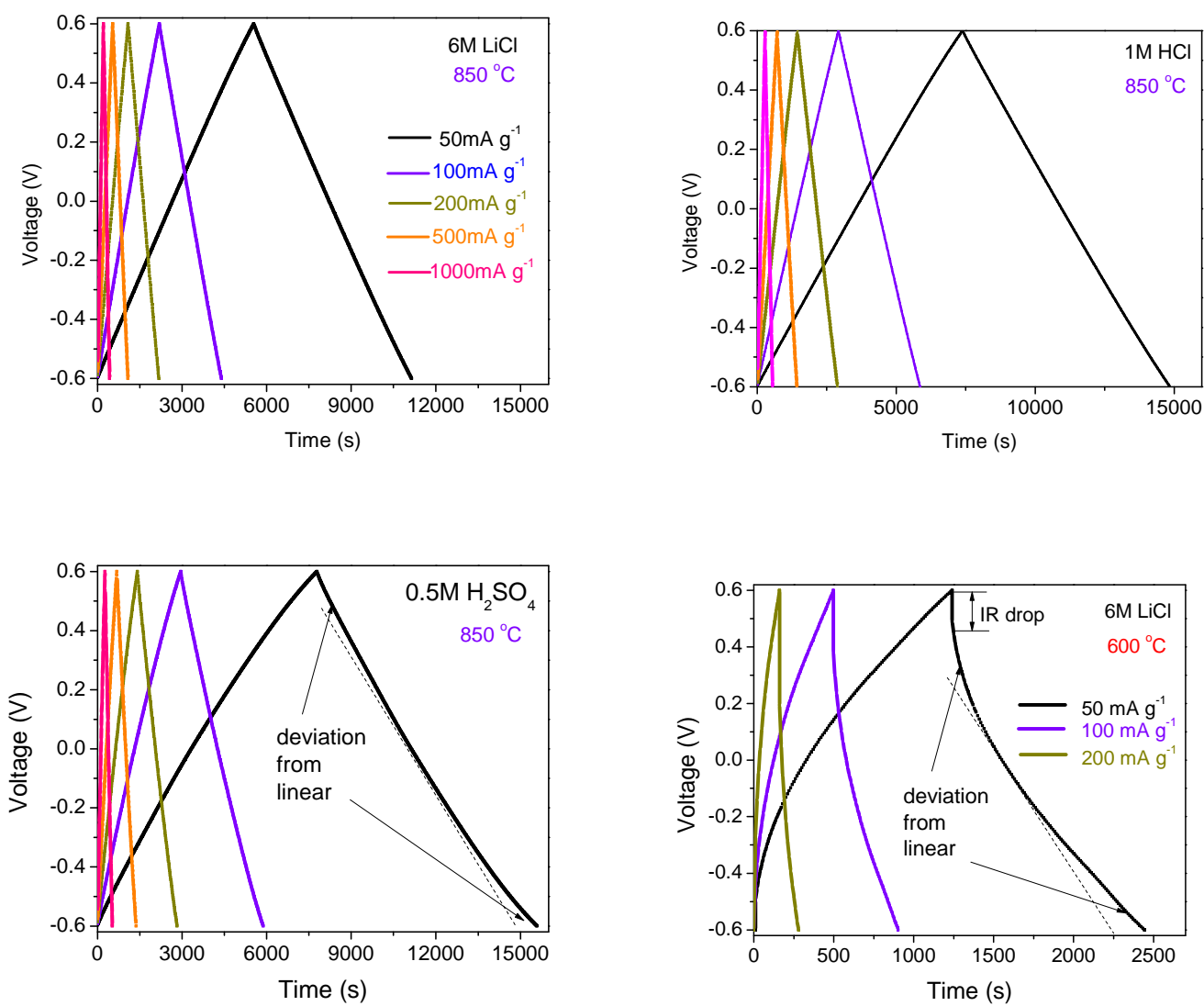

Figure 12. Charge-discharge characterization. Voltage profile of activated carbon synthesized at $850 \cong \mathrm{C}$ at different current densities $\left(50,100,200,500\right.$ and $1000 \mathrm{~mA} \mathrm{~g}^{-1}$ ) in (a) $6 \mathrm{M} \mathrm{LiCl}$, (b) $1 \mathrm{M} \mathrm{HCl}$ and (c) $0.5 \mathrm{M}$ $\mathrm{H}_{2} \mathrm{SO}_{4}$. (d) Voltage profile of activated carbon synthesized at $600 \circ \mathrm{C}$ at different current densities $(50,100$ and $200 \mathrm{~mA} \mathrm{~g}^{-1}$ ) in $6 \mathrm{M} \mathrm{LiCl}$. 

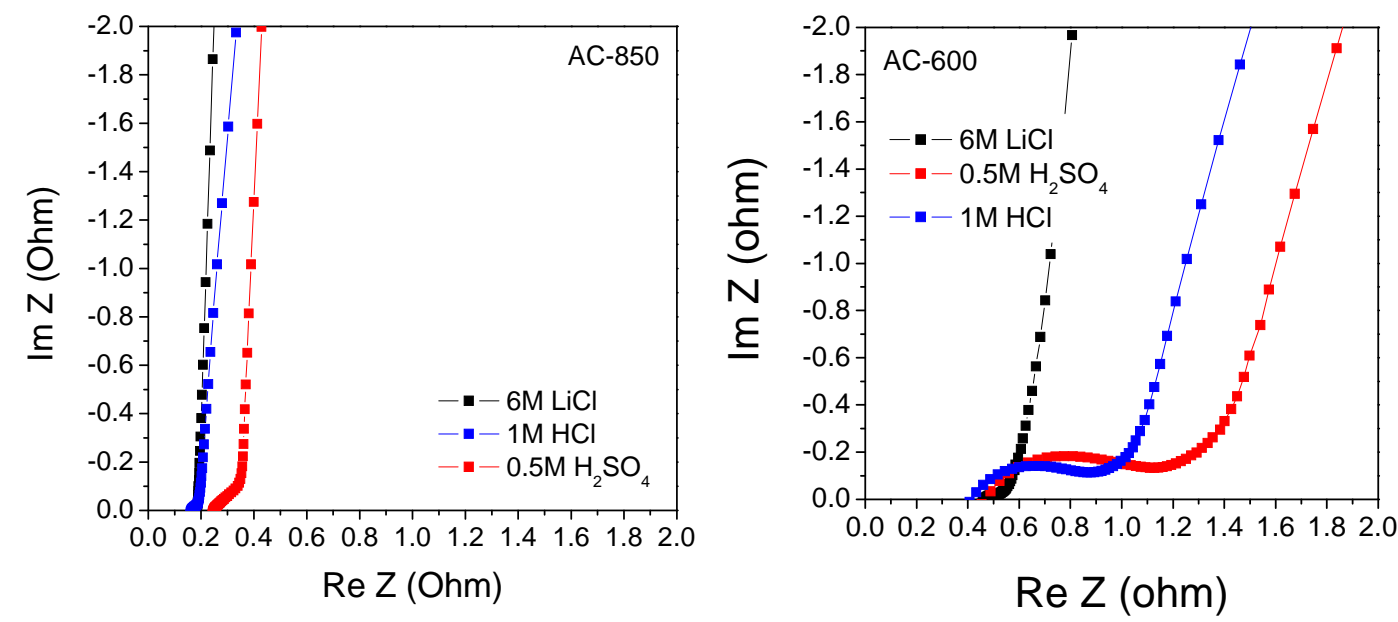

Figure 13. Nyquist plot of (a) AC-850 and (b) AC-600 in different electrolytes. 

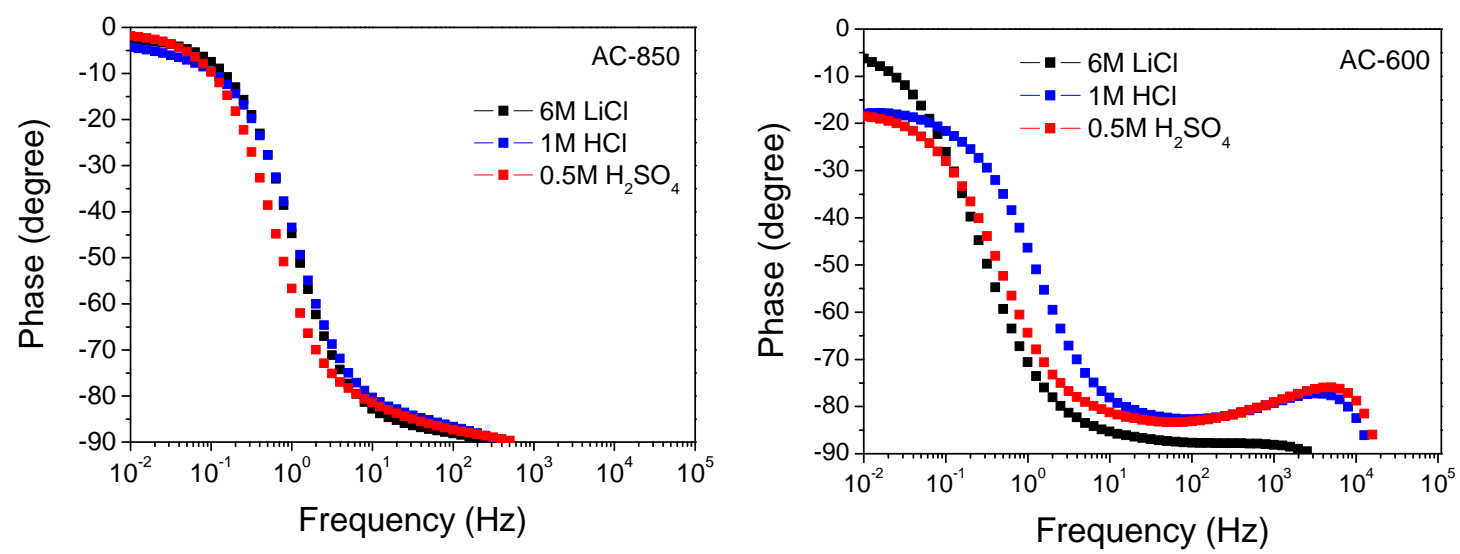

Figure 14. Bode plot of (a) AC-850 and (b) AC-600 in different electrolytes. 